\title{
BI APPLICATION IN FINANCIAL SECTOR - CREDIT SCORING OF RETAIL LOANS USING A HYBRID MODELING APPROACH
}

\author{
Prof. S. Chandrasekhar, B. Tech., M. Tech. (IIT - Kanpur), Ph. D. (U.S.A.) \\ Chair Professor and Area Chair - I.T. \\ FORE School of Management, New Delhi, B-18, Qutub Institutional Area, New Delhi - 110016 (India) \\ Email-sch@fsm.ac.in
}

\begin{abstract}
Retail Loans now-a-days form a major proportion of Loan Portfolio. Broadly they can be classified as (i) Loans for Small and medium Sector and (ii) Loans for Individuals. The objective of Credit Scoring is that we use enough of precaution before the sanction of the loan so that the loans do not go bad after disbursement. This will increase to the bottom line of the financial institution and also reduce the Credit Risk.
\end{abstract}

Techniques used to perform Credit Scoring Varies for the above two classes of loans. In this paper, we concentrate on the application of Credit Scoring for individual or so called personal loans like - Auto loan, buying goods like Televisions, Refrigerators etc. Large numbers of loans are being disbursed in these areas. Though the size of the loan may be small, when compared to Small/Medium Scale Industry, if one does not control the defaults, the consequences will be disastrous.

From the characteristics of borrower, product characteristics a Credit Score is computed for each applicant. If the Score exceeds a given threshold loan is sanctioned. If it is below the threshold, loan is sanctioned. If it is below the threshold, loan is rejected. In practice a buffer zone is created near the threshold so that those Credit Scores that fall in buffer zone, detailed investigation will be done before a decision is taken.

Two broad classes of Scoring Model exists (i) Subjective Scoring and (ii) Statistical Scoring.

Subjective Scoring is based on intuitive judgement. Subjective Scoring works but there is scope for improvement one limitation is prediction of risk is person dependent and focuses on few characteristics and may be mistakenly focusing on wrong characteristics.

Statistical Scoring uses hardcore data of borrower characteristics, product characteristics and uses mathematical models to predict the risk. The relation is expressed in the form of an equation which finally gets converted to a score. Subjectivity will be reduced and variable(s) that are important to scoring are identified based on strong mathematical foundation.

Different Models have been used in Credit Scoring like Regression, Decision Tree, Discriminate Analysis and Logistic
Regression. Most of the times, a single model is used to compute the Credit Score. This method works well when the underlying decision rule is simple and when the rule becomes complex, the accuracy of the model diminishes very fast.

In this Research Paper, a combination of Decision Tree and Logistic Regression is used to determine the weights that are to be assigned to different characteristics of the borrower. Decision Tree is used at first level of analysis to narrow down the importance of Variables and overall weights that needs to be assigned. It is also used for optimum groupings of numeric and non-numeric Variables. At second level, Logistic Regression is used to compute odd ratios a variant of probability, which in turn is used to assign weights for an attribute and to individual levels in an attribute.

This has been tested on real life data and found to work better compared to methods using a single stage models. An accuracy of around $80 \%$ in decision is obtained which is good for any modeling study as there is no model which gives $100 \%$ accuracy.

The next Section explains the Methodology, Data Used and Results.

SPSS Software has been used for Model Building and Data Analysis

\section{Methodology Adopted}

A sample data of about Three Hundred and Seventy Nine Records were taken from a Bank Database. The following Variables were used for the Analysis:- 


\begin{tabular}{|l|c|l|}
\hline SEX & $:$ & MALE/FEMALE \\
\hline AGE & $:$ & CONTINUOUS \\
\hline TIME-AT-ADDRESS & $:$ & HOW LONG THE CUSTOMER IS LIVING AT THIS ADDRESS \\
\hline RESIDENCE STATUS & $:$ & OWNER, RENTED \\
\hline TELEPHONE & $:$ & YES/NO \\
\hline TIME-BANK & & HOW LONG IS CUSTOMER WITH THE BANK ; NUMERIC \\
\hline HOME EXPENSES & $:$ & NUMERIC \\
\hline DECISION & $:$ & SANCTIONED/REJECTED \\
\hline OCCUPATION & $:$ & CREATIVE, DRIVER, GUARD, LABOURER, MANAGER, OFFICE- \\
& & STAFF, PRODUCTION, PROFESSIONAL, SALES, SEMI-PRODUCTION \\
\hline JOB STATUS & $:$ & GOVERNMENT, PRIVATE, SELF-EMPLOYED \\
\hline TIME-EMPLOYED & $:$ & LENGTH OF EMPLOYMENT - NUMERIC \\
\hline LIAB. - REFERENCE & $:$ & TRUE/FALSE \\
\hline ACC. - REFERENCE & $:$ & GIVEN/OTHER INSTRUCTIONS \\
\hline BALANCE & $:$ & NUMERIC \\
\hline
\end{tabular}

DEPENDENT VARIABLE $\quad: \quad$ DECISION

\section{INDEPENDENT VARIABLE(S) : $\quad$ ALL OTHERS}

Since the Independent Variables are a Combination of Numeric and Non-numeric Variable(s), and Dependent Variable Nonnumeric, Decision Tree using Chi-square Interaction Detection (CHAID) Method is used to analyse the data. We cannot use regression. Out of 379 Cases, 53\% (201) Cases are rejected and 47\% (178) have been accepted.

Summary of the Decision Tree is given below:-

\begin{tabular}{|l|l|l|}
\hline \multicolumn{2}{|c|}{ Model Summary } \\
\hline Specifications & Growing Method & CHAID \\
\cline { 2 - 3 } & Dependent Variable & DECN_RECD (DECISION) \\
\cline { 2 - 3 } & Independent Variables & $\begin{array}{l}\text { SEX, AGE, TIME_AT_ADDRESS, RES_STATUS, } \\
\text { TELEPHONE, OCCUPATION, JOB_STATUS, } \\
\text { TIME_EMPLOYED, TIME_BANK, LIAB_REF, } \\
\text { ACC_REF, HOME_EXPN, BALANCE }\end{array}$ \\
\hline Results & $\begin{array}{l}\text { Independent Variables } \\
\text { Included }\end{array}$ & TIME_BANK, TIME_EMPLOYED \\
\cline { 2 - 3 } & Number of Nodes & 8 \\
\cline { 2 - 3 } & $\begin{array}{l}\text { Number of Terminal } \\
\text { Nodes }\end{array}$ & 5 \\
\cline { 2 - 3 } & Depth & 2 \\
\hline
\end{tabular}


Graphical Tree is shown below:-

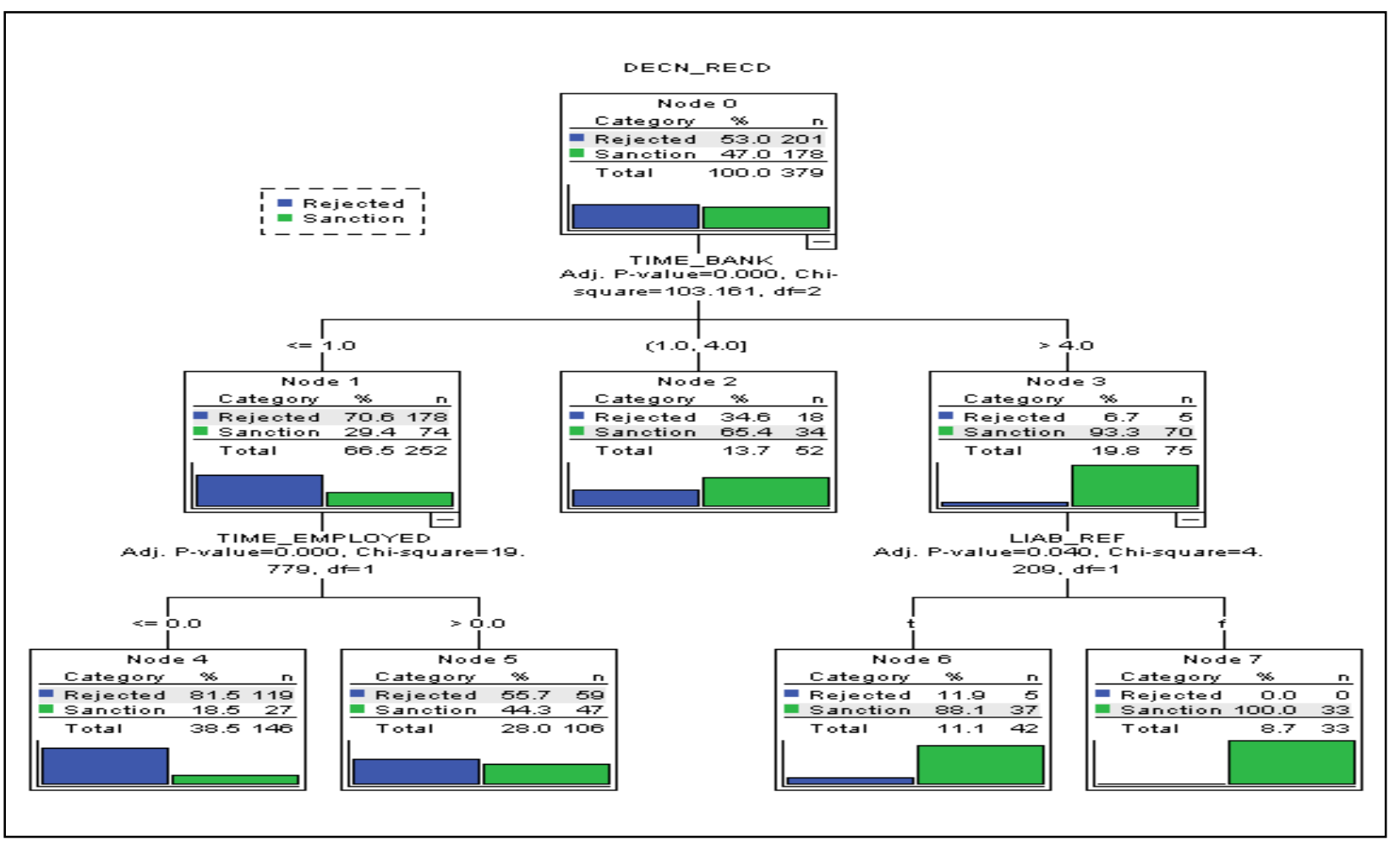

Classification Accuracy of the Tree is given below:-

\begin{tabular}{|l|c|c|c|}
\hline \multicolumn{3}{|c|}{ Classification } \\
\hline \multirow{2}{*}{ Observed } & \multicolumn{3}{|c|}{ Predicted } \\
\cline { 2 - 4 } Rejected & Rejected & Sanction & Percent Correct \\
\hline Sanction & 178 & 23 & $88.6 \%$ \\
\hline Overall Percentage & 74 & 104 & $58.4 \%$ \\
\hline $\begin{array}{l}\text { Growing Method: CHAID } \\
\text { Dependent Variable: DECN_RECD }\end{array}$ & $33.5 \%$ & $74.4 \%$ \\
\hline
\end{tabular}

If you look at Model Summary Table, the model has identified Time-Bank, Time-Employed, as important Variables for Prediction and it has rejected all other Variables. The overall classification accuracy is about $74 \%$. All Non-numeric Variables like Occupation, Job Status, Residential Status etc. are ignored.

One reason for rejecting all other Non-numeric Variables may be due to sample size of the data set and heavy influence of Numeric Variables. In practice, Non-numeric Variables also play an important role in Credit Scoring. To validate this assumption, in the next step, Two Decision Trees have been built - One taking only Numeric Independent Variables: Time-At-Address, Time-Bank, Home-Expenses, and Balance. The classification accuracy is $77 \%$.

Then for Second Tree using only Non-numeric Independent Variables like Occupation, Job Status, Residence Status etc. are considered. The Classification accuracy was $66 \%$ which is not low. The Dependent Variable is Decision. 
Hence one can include both Numeric and Non-numeric Variable but with a slightly higher weightage for Numeric compared to Non-numeric Variables. The weights will be inversely proportional to error i.e. if the error is high weight will be less and vice-versa.

So, the overall weightage assigned to Numeric Variables are: $(77 /(77+66)) \times 100=54 \%$; it is $(66 /(77+66)) \times 100=46 \%$.

The next step is to assign Individual Weights to different levels within Numeric and Non-numeric Variables keeping overall weights to $54 \%$ and $46 \%$.

Logistic Regression is used for assigning Individual Weights.

Logistic Regression gives a functional relation between Dependent and Independent Variables. The only difference between Logistic Regression and Usual Regression is the Dependent Variable is categorical and has only two states of nature like Loan Application Accepted/Rejected, Person defaulting a loan/not defaulting etc.

The functional form can be expressed as:

$$
\text { : }
$$

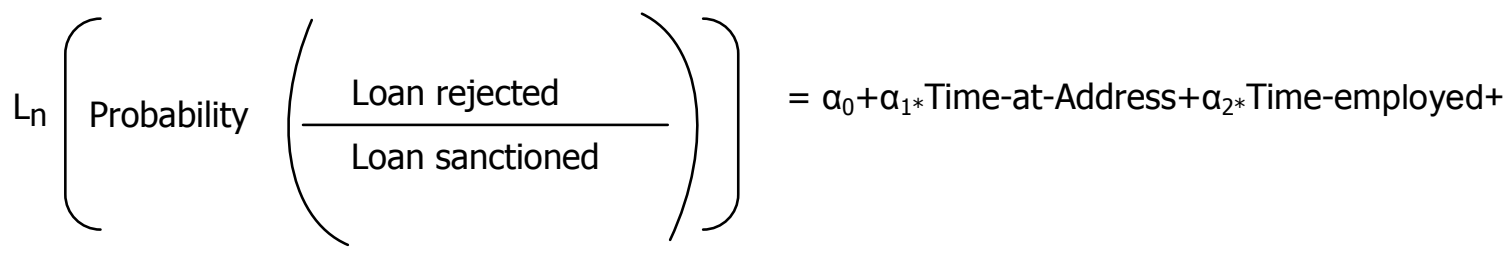

$\alpha_{0}, \alpha_{1}, \alpha_{2}, \ldots \ldots \ldots \ldots \ldots \ldots$............ called the Logit Coefficients and will be estimated using sample data using maximum likelihood estimation.

Out of all the Independent Variables taken for model building, I have explained below methodology of assigning Individual Weights for different attribute level values. One example for Numeric Variable and another for Non-numeric Variable. This methodology is repeated for all other Numeric and Nonnumeric Independent Variables.

When all the Numeric Variables are taken as Independent Variable(s), and DECISION as Dependent Variable, Logistic Regression is run. Based on the significance the following Variables are retained:-
The numbers in the bracket indicate the odd ratio and all are significant at 5\%. Alternatively what it means is these Coefficients are correct $95 \%$ of time. Only $5 \%$ of time they may be wrong. COX_NELL R Square of about 0.4 Validates the Hypothesis, that Logistic Regression fits the data. If value of COX_NELL R Square is below 0.05 one can conclude Logistic Regression does not fit the data.

Out of Total Weight of $54 \%$ assigned to all Numeric Variables, the break-up of Weights for THREE significant Numeric Variables are worked out as follows using the Logit Coefficients:-

TIME-BANK $=(1.53 /(1.53+1.20+1.0)) \times 54=22$

TIME-EMPLOYED $=(1.20 /(1.53+1.20+1.0)) \times 54=17$

BALANCE $=(1.0 / 1.53+1.20+1.0)) \times 54=15$
At the next level let us take one Variable used in scoring i.e. TIME-BANK. The total weight for this is 22 and this Variable takes on values in the range: 0-67. The total weight of 22 needs to be broken into different bins and the binning should be automatic instead of person dependent.

For this, the methodology used is as follows:-

The histogram was displayed and using Visual binning techniques the Variable TIME-BANK was binned into 5 bins. This may not be optimum. The next step was to use the Decision Tree to automatically determine the number of bins. The Dependent Variable is DECISION and Independent Variable is TIME-BANK grouped into 5 bins. The output of the Decision Tree is given below:- 


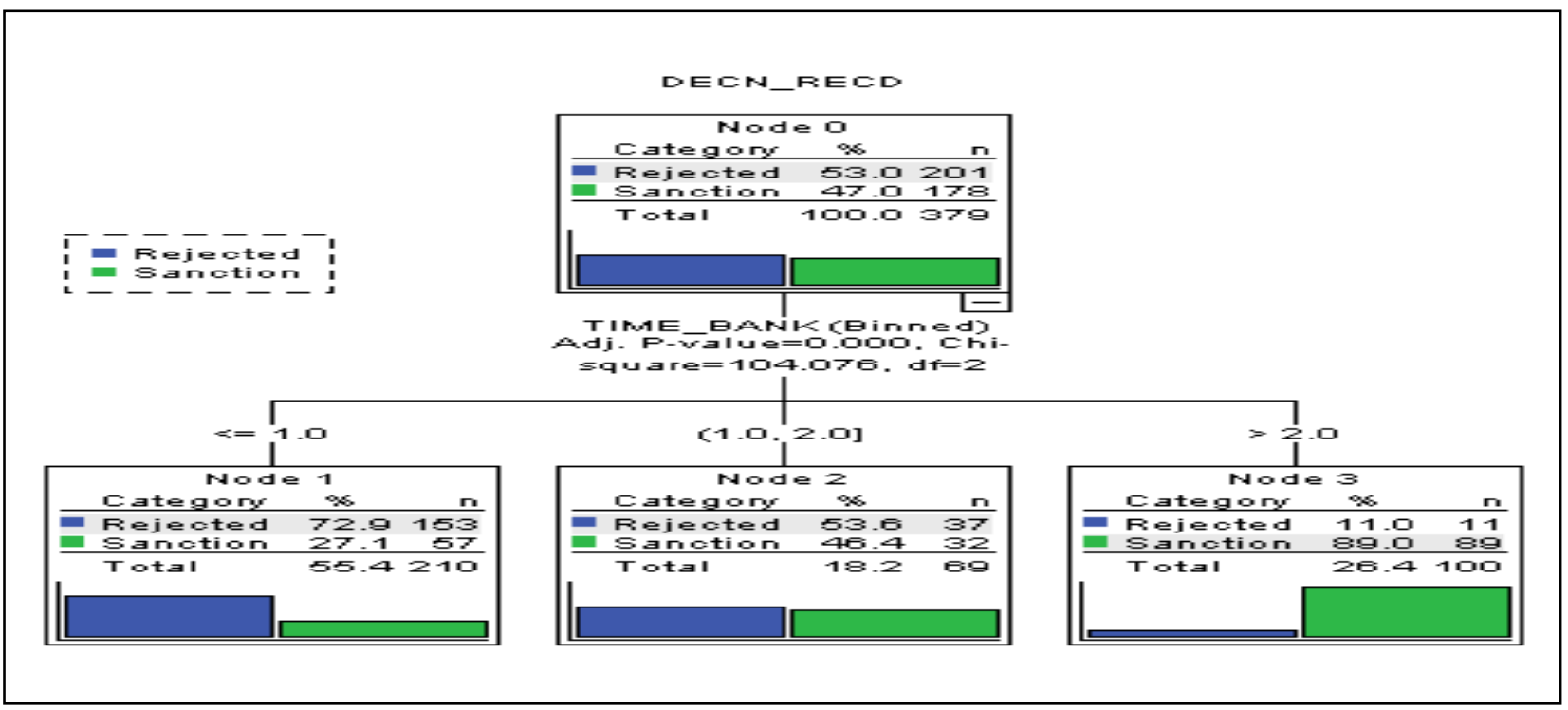

Looking at the Tree output shown above it is clear that only THREE bins are optimum compared to manual FIVE bins. The following bins are given as under:-

\begin{tabular}{|l|l|l|}
\hline TIME-EMPLOYED & $\leq 1.0$ & Bin 1 \\
\hline $1.0<$ TIME-EMPLOYED & $\leq 3.0$ & Bin 2 \\
\hline TIME-EMPLOYED & $>3.0$ & Bin 3 \\
\hline
\end{tabular}

Again Logistic Regression is used to determine Individual Weights for each bin.

The Logit Coefficients for Bin 1, Bin 2 and Bin 3 are 0.4, 3.0 and 19.0 respectively.

The weights assigned to different bins are:

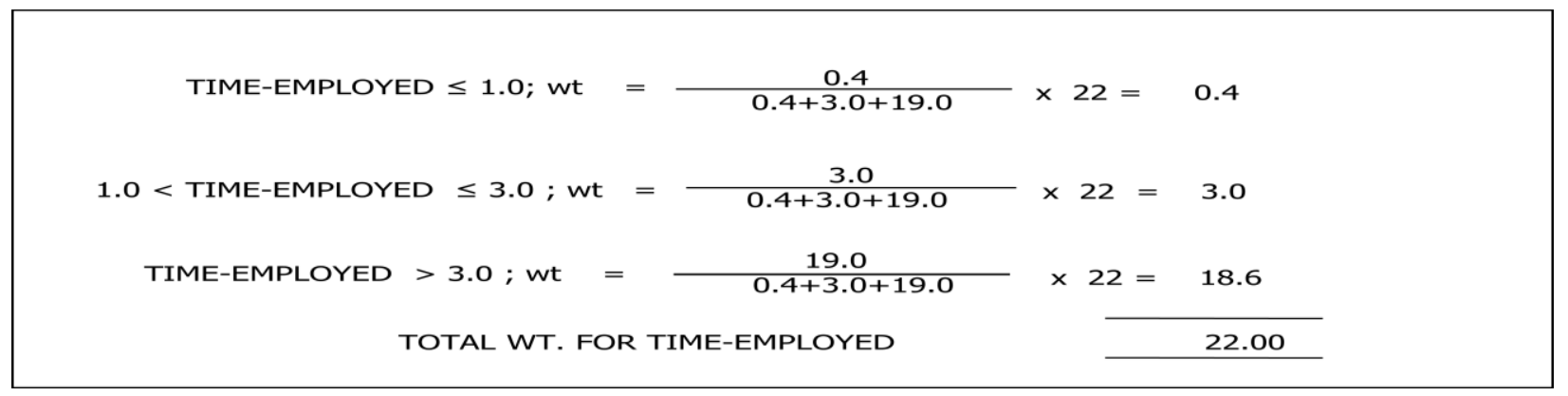

Similar process is repeated for other Two Variables i.e. TIME-WITH-BANK and BALANCE.

When the decision tree model was applied to Non-numeric Variables like JOB-STATUS, OCCUPATION, RESIDENTIAL STATUS, ACC.-REF. and TELEPHONE only TWO Variables were significant. They were: OCCUPATION, JOB STATUS.
Total of $46 \%$ weight for Non-numeric Variables is split into two parts using the odd ratios. Result: OCCUPATION: 40 and JOB STATUS: 6. Using Decision Tree and Logistic Regression the Weights for different attribute values under Occupation is given below:- 


\begin{tabular}{|l|r|l|r|}
\hline Professional & 12.5 & Creative & 2.80 \\
\hline Semi-professional & 9.5 & Sales & 1.92 \\
\hline Office Staff & 5.2 & Driver & 1.00 \\
\hline Production & 2.9 & Labourer & 1.27 \\
\hline \multicolumn{2}{|r|}{ TOTAL } & 0.86 \\
\hline \multicolumn{2}{|r|}{} & & Guard \\
\hline
\end{tabular}

For Job-Status Weights are:

\begin{tabular}{|c|c|}
\hline Government & 2.4 \\
\hline Self-employed & 2.5 \\
\hline Private & 1 \\
\hline TOTAL & 6.0 \\
\hline
\end{tabular}

When once the Weights for all Independent Variables of significance have been computed using Decision Tree Logistic Regression iteratively the data will be ready for scoring.
The Credit Score for each Record will be sum of Weight of the Bin to which each attribute level falls. Data will be sorted in Descending Order of Credit Score.

A part of Scored Data is given below:-

\begin{tabular}{|c|c|c|c|c|c|c|c|c|c|}
\hline $\begin{array}{l}\text { DECN_REC } \\
\text { D }\end{array}$ & $\begin{array}{l}\text { BAL_BIN } \\
\text { ED_TWO } \\
\text { LVL }\end{array}$ & $\begin{array}{l}\text { TIMES- } \\
\text { EMPL_B } \\
\text { IN3 }\end{array}$ & $\begin{array}{l}\text { TIME-_- } \\
\text { BNK_BI } \\
\text { N3 }\end{array}$ & $\begin{array}{l}\text { TIMES } \\
\text { EMPLO } \\
\text { YED_S } \\
\text { CORE }\end{array}$ & $\begin{array}{l}\text { TIME_B } \\
\text { ANK_S } \\
\text { CORE }\end{array}$ & $\begin{array}{l}\text { JOB_S } \\
\text { TAT_S } \\
\text { CORE }\end{array}$ & $\begin{array}{l}\text { OCCUPA } \\
\text { TION_S } \\
\text { CORE }\end{array}$ & $\begin{array}{l}\text { BALAN } \\
\text { CE_SC } \\
\text { ORE }\end{array}$ & $\begin{array}{l}\text { Total_cre } \\
\text { dit_score }\end{array}$ \\
\hline Rejected & 2 & 1 & 1 & 0.9 & 0.4 & 1 & 9.5 & 0.5 & 12.3 \\
\hline Rejected & 2 & 1 & 1 & 0.9 & 0.4 & 1 & 1 & 0.5 & 3.8 \\
\hline Rejected & $\overline{2}$ & 2 & 1 & 4.4 & 0.4 & 2.4 & 1.92 & 0.5 & 9.62 \\
\hline Sanction & $\overline{2}$ & $\overline{1}$ & 2 & 0.9 & 3 & 1 & 9.5 & 0.5 & 14.9 \\
\hline Sanction & $\overline{2}$ & 1 & 3 & 0.9 & 18.6 & 1 & 9.5 & 0.5 & 30.5 \\
\hline Sanction & $\overline{1}$ & $\mathbf{1}$ & 3 & 0.9 & 18.6 & 1 & 12.5 & 13.5 & 46.5 \\
\hline Rejected & 2 & 1 & 1 & 0.9 & 0.4 & 1 & 2.9 & 0.5 & 5.7 \\
\hline Sanction & $\overline{2}$ & 2 & 3 & 4.4 & 18.6 & 1 & 12.5 & 0.5 & 37 \\
\hline Rejected & $\overline{2}$ & 1 & 2 & 0.9 & 3 & 1 & 5.2 & 0.5 & 10.6 \\
\hline Rejected & 2 & 2 & 2 & 4.4 & 3 & 1 & 2.8 & 0.5 & 11.7 \\
\hline Rejected & 2 & $\mathbf{1}$ & 1 & 0.9 & 0.4 & 2.4 & 2.8 & 0.5 & \\
\hline Sanction & 1 & 3 & 3 & 11.8 & 18.6 & 1 & 2.8 & 13.5 & 47.7 \\
\hline Rejected & 2 & 1 & 1 & 0.9 & 0.4 & 1 & 2.8 & 0.5 & 5.6 \\
\hline Rejected & 2 & $\mathbf{1}$ & 2 & 0.9 & 3 & 1 & 1.92 & 0.5 & 7.32 \\
\hline Sanction & 2 & $\mathbf{1}$ & 3 & 0.9 & 18.6 & $\mathbf{1}$ & 2.8 & 0.5 & 23.8 \\
\hline Sanction & 2 & 3 & $\mathbf{1}$ & 11.8 & 0.4 & 2.4 & 2.9 & 0.5 & 18 \\
\hline Rejected & 2 & 3 & $\mathbf{1}$ & 11.8 & 0.4 & 1 & 1.95 & 0.5 & 15.65 \\
\hline Sanction & 2 & 3 & 3 & 11.8 & 18.6 & 2.4 & 2.9 & 0.5 & 36.2 \\
\hline Rejected & 2 & 1 & 1 & 0.9 & 0.4 & 2.4 & 1 & 0.5 & 5.2 \\
\hline
\end{tabular}

Now one can try different cut off's and see how the accuracy changes. As an example let us put a cut off score of 14 i.e. for these whose Credit Score is greater than or equal to 14, Loan will be sanctioned and for those less than 14, the loan will be rejected. The total number rejected with this threshold is 165 out of Total Number of 201 rejected cases. The accuracy of rejection is $82 \%$. Similarly, there are 124 accept cases for threshold $\geq 14$.

Total no. of accept cases: 178

Classification Accuracy of accept: $124 / 178 \times 100=70 \%$

Overall Classification Accuracy $=76 \%$ : (Accept to Accept + Reject to Reject)/Total Cases 


\section{CONCLUSION}

The paper illustrates Hybrid model for Credit Scoring Using Decision Tree and Logistic Regression in a recursive manner. SPSS Software has been used for Model building and Data analysis. It also optimizes the Bins for both numeric and nonnumeric Variables using Decision Tree. Many times subjective Weights are used based on experience of loan manager. This paper explores how financial institution specific data can be used to derive the Weights automatically. One can compare and fine tune the subjective scores based on actual data. Further work involves integration of an optimization technique like Linear/Goal programming to fine tune the Weights.

\section{REFERENCES}

[1] Credit Scoring and its applications, Lyn Thomas Et.al, SIAM Publication, June 2002

[2] Credit Risk Score Cards : Developing and Implementing Intelligent Credit Scoring,Naeem Siddiqi, Johnwiley and SAS Series, 2005

[3] Credit Scoring for Risk Managers, Elizabeth Mays and Niall Lynar, Create Space, 2011

[4] Managing Consumer Lending Business, David Lawrence, Solomon Lawrence Partners, July 2002

[5] Credit scoring systems: A critical analysis, N. Capon (1982), J. Marketing, 46, 82-91

[6] Recent developments in the application of credit scoring techniques to the evaluation of commercial loans, R.A. Eisenbeis (1996), IMA J. Math. Appl. Business Indust., 7, 271-290

[7] An Introduction to Credit Scoring, Athena Press, E. M. Lewis (1992), San Rafael, CA

[8] Methodologies for classifying applicants for credit, in Statistics in Finance, L. C. Thomas (1998), D. J. Hand and S.D. Jacka, eds., Arnold, London, 83-103

[9] Credit Scoring and Credit Control, L.C.THOMAS, J. N. Crook and D. B. Edelman (1992), Oxford University Press, Oxford

\section{BACK GROUND OF PROF. S. CHANDRASEKHAR}

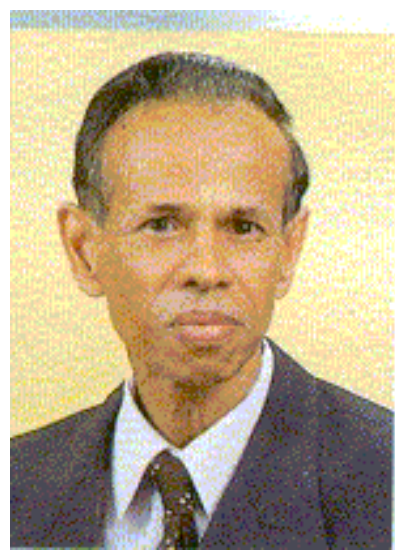

Dr.S.Chandrasekhar is currently chair Professor \& also Officiated as Director(during April 2009-Jan 2010) at FORE School of Management, New Delhi. He joined FORE SCHOOL in July 1998 as Senior Professor and later on became chair professor Director-IT and subsequently Director(Officiating). $\mathrm{He}$ is also heading the software development at Fore School of Management which are developing proto type of products in the area of Business Intelligence,Risk Management,Customer Relations Management.He has a total of about 34years of experience in R\&D,Academic \& Industry in the area of IT and Quantative Methods.

He has been awarded the prestigious NASSCOM-DEWANG MEHTA national award for Best teacher in IT among mgmt Institutes in the country.

Took part in a number of seminars \& conferences as a speaker \& also participated in panel discussion.

Prior to this he worked at Indian Institute of Management, Lucknow for about ten years as Professor in the area of Computers \& information Systems. Was also the area Chair Quantitative \& Information Systems Group , Admissions Chairman \& Member Governing Board of IIM Lucknow.

Joined IIM Lucknow \& Fore School Of Mgmt in initial years of formation \& contribute to the growth.

He holds a Bachelor's degree in Electrical Engineering, Master's degree in Information Technology from IIT, Kanpur and Doctorate in Information Systems from University of Georgia, USA. Worked in India, USA and Canada in reputed organizations like TIFR, ISRO, NRSA,FORD Aerospace Corporation, National Research Council before joining IIM, Lucknow. Awarded UNDP fellowship for study in Advanced Computer Systems design.

Worked in the area of Neural Network, Forecasting using Statistical Techniques, Mathematical Modeling, Data Warehousing/Data Mining.

He worked as visiting Professor at Manchester Business School, U.K. for about a year with Prof.Douglas Wood. He has taught courses in the area of Information Technology, Decision Sciences and Forecasting. He also held other Academic administrative position at IIM Lucknow .

Professor S.Chandrasekhar is a Fellow of the Institution of Electronics \& Telecommunication Engineers, Fellow of Institution of Engineers, Fellow of Association for Information Systems and Senior Member of Computer Society of India. Published about 30 papers in National and International Journals and also presented papers at various International Conferences, Guided students for their Masters and Doctoral Work.

$\mathrm{He}$ is also in the committee constituted by Ministry of Information Technology Govt Of India on Knowledge Management In Indian Languages, Advisor to Central Statistical Organisation for building a national Datawarehouse.

Also a regular speaker in quite a few reputed Institutes like IITM, IIM,IIFT,RBI Training College,National Insurance Academy National Institute Of Bank mgmt etc. 